\title{
Where Have All The Ethics Gone?
}

T his question posed a greater dilemma than I could ever have expected. I reasoned because there is such an increasing interest in ethics and so much is said and presumably written about it that to find all the answers one would do a simple analysis of the physiotherapy literature. I could not have been more mistaken! So little is written about ethical issues in the physiotherapy literature that I decided to probe more deeply.

According to Julius Sim (1997), there is increasing freedom to criticize institutions in society that had previously been above such scrutiny and critique. These institutions are for instance the church, the judiciary, education and medicine. Many medical ethical dilemmas are concerned with issues such as organ transplantation, appropriate life-support, genetic engineering and the medical treatment of chronic diseases. These issues are frequently addressed in the media and in professional journals but infrequently by physiotherapists. Perhaps the reason for the apparent lack of physiotherapy involvement in ethical issues is the fact that issues involving physiotherapists are often not immediately apparent. Physiotherapists, according to $\operatorname{Sim}$ (1997), are involved with more mundane issues

\section{EDITOR:}

- C.J. Eales, PhD

University of the Witwatersrand

\section{Assistant Editor:}

A. Stewart, MSc

University of the Witwatersrand

\section{EDITORIAL BOARD:}

National Members

- M. Goodman, PhD

- S.L. Amosun, PhD

University of the Western Cape

- P. Gounden, PhD

University of Durban-Westville

- M. Papadoupolos, MSc

University of Pretoria

- M. Faure, MPhil

University of Stellenbosch

- N. Mbambo, MSc

MEDUNSA

\section{INTERNATIONAL MEMBERS}

- A. Akinpelu, $\mathrm{PhD}$

University College Hospital,

Ibadan, Nigeria

- T.H.A. Kolobe, $\mathrm{PhD}$

University of Illinois, Chicago

K. Shepard, PhD

Temple University, Philadelphia

- C. Partridge, $\mathrm{PhD}$

University of Kent, Canterbury such as deciding on priorities within a given caseload especially when resources have been decreased significantly. Those of us working in the public sector will be able to identify closely with this problem. We know the agony of refusing outpatient trearment to the elderly lady who has been coming to the department for many years. The reason we can no longer tend to this patient is simply because we have had to close down the out-patient department in order to sustain essential services to patients for whom the physiotherapy input is critical. And that brings us to the question whether some patients are more deserving of treatment than others. But on what grounds and how do we make such judgements?

Another burning ethical consideration is whether the physiotherapist should always get "informed consent" prior to treating a patient. If this is the case from whom should the consent be oblained. Is the medical practitioner's directive all that is necessary for the unconscious patient or should the family be consulted and informed about the frequency and cost of the therapy? And what if the prescribing doctor has erred in his/her judgement that physiotherapy is indeed indicated? Do we simply proceed on "Doctor's orders" or do we inform the prescribing doctor of the inappropriateness of the treatment ordered. Are we willing to take on the chagrin of doctors and the possibility that we may loose their professional support or do we do as instructed and all "live happily ever after"? In my professional experience I have often observed such a symbiosis.

Consideration must also be given to the ethical issue when persuading a patient to continue with treatment when they clearly have indicated an unwillingness to do so. Is it also ethical to continue with treatment because the doctor ordered it even though the treatment is proving ineffective? One would think that the answer is simple and clear, however, there is often unwillingness on the part of the physiotherapist to deal with these issues in a positive and conclusive manner.

The issue of causing patients discomfort and pain is one that I have always felt very strongly about. Under what circumstances is this permissible? Occasionally heart-rending cries of agony are heard from patients and children that I find myself totally appalled by the agony of the recipient of the well-intended therapeutic intervention. Could such a situation ever be ethical?

Can patients be misled as to their diagnosis and the nature of the treatment given to them? Will the intervention be palliative or curative? Should the referring doctor be ethically responsible and if so, what is the role of the physiotherapist? The AIDS pandemic is certainly drawing our attention to these issues more and more. And staying with this issue prompts the question of with whom is it permissible to discuss personal information and treatment details of patients? The extent to which physiotherapists could be expected to expose themselves to risk when treating patients is also a burning ethical issue.

Two further issues that should be considered is to what extent can physiotherapists allow themselves to be influenced by third-party reimbursements and the very important issue of dealing with colleagues whom we consider incompetent and whose conduct may be regarded as unethical!

Professionals should learn to protect their professions. Resulting from a few most unfortunate cases in England around a number of notorious medical practitioners such as the recently reported case of "dr. Death", there is now growing certainty that that the values and the preferences that control the delivery of health care should not be those of professionals alone. Health professionals seem to be unable to do this effectively!

Finally, the issue of the documentation of patient records should be considered. In a recent survey the appalling state of the patient record was exposed. Frequently no records are kept and when available records are incomplete and inadequate. Records should also be stored for at least two years in case there are queries or disciplinary hearings.

All of us working in the health sector should be committed to ethical behaviour, which is behaviour that is morally correct. This behaviour is described by a code of ethics, which is unique and central to the profession and indeed can be considered as part of the definition of the profession. Narina Gilder admirably addressed issues such as accountability, transparency and responsibility in the September 1999 edition of Physioforum. I would like to invite the readership to consider the ethical issues and dilemmas we deal with in Africa and to send case studies that highlight these issues for publication in the Journal.

Let us make 2001 a ethical and prosperous new year!

SIEIII EALES (Editor)

\section{REFERENCE:}

Sim J 1997 Ethical Decision Making in Therapy Practice. First edition, Butterworth-Heinemann 